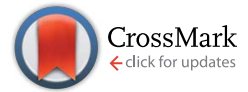

Cite this: RSC Adv., 2016, 6, 82783
Received 13th June 2016 Accepted 26th August 2016

DOI: $10.1039 / c 6 r a 15343 g$

www.rsc.org/advances

\section{An efficient DFT method of predicting the one-, two- and three-bond indirect spin-spin coupling constants involving a fluorine nucleus in fluoroalkanes $\uparrow$}

\begin{abstract}
Adam Gryff-Keller* and Przemysław Szczeciński
The values of the indirect nuclear spin-spin coupling constants for a series of aliphatic fluorocompounds have been calculated using DFT-based methods and compared with the experimental values of these parameters. The set of the molecular objects contained four fluoromethanes, five fluoroethanes, two fluorocyclopropanes, and eleven fluorocompounds containing either five-membered or six-membered rings. The effectiveness of three hybrid functionals, B3LYP, PBEO and BHandH and three basis sets, $6-311++G(2 d, p)(s), 6-311++G(3 d f, 3 p d)(m)$ and aug-pcJ-3-2006 (l) has been checked. In order to compare the results concerning various types of coupling constants and obtained by various methods, a prediction-quality criterion has been proposed. It has been found that only the BHandH functional ensures calculating the proper values of one-bond fluorine-carbon and two-bond fluorine-fluorine coupling constants. For this functional application of the $s$ basis, the smallest of the bases tested, has already yielded acceptable good results. The DFT BHandH/s PCM method has also provided the proper values of ${ }^{n} J(F, H)(n=1,2,3)$ and ${ }^{n} J(F, C)(n=2,3)$ parameters. On the other hand, the analysis of the limited number of the results concerning ${ }^{1} J(\mathrm{C}, \mathrm{H})$ coupling constants has pointed out that in this case this method is less effective than the DFT PBEO/I PCM method.
\end{abstract}

\section{Introduction}

Fluoroorganic chemistry has been developing for a long time. Numerous synthetic methods aimed at massive or selective fluorination of various organic compounds have been elaborated. The fluorine atom can replace virtually any hydrogen in a molecule and a huge number of fluoroorganic compounds have been synthesized., ${ }^{1,2}$ The fluorine substituent is strongly electronegative and, simultaneously, $\pi$-electron donating, as it possesses lone electron pairs which can efficiently conjugate to molecular $\pi$-electron systems. Introduction of such a substituent into a molecule usually remarkably modifies its physicochemical and biological properties. Substances obtained this way play an important role in chemistry as synthons or solvents and in industry as materials of unique features, such as various fluoropolymers. ${ }^{3}$ Moreover, many fluoro derivatives are biologically active substances and are used in medicine as important drugs or anesthetics. ${ }^{4}$ Some fluorocompounds are highly toxic and, unfortunately, have been used as chemical weapons (sarin,

Faculty of Chemistry, Warsaw University of Technology, Noakowskiego 3, 00-664 Warszawa, Poland. E-mail: agryff@ch.pw.edu.pl

$\dagger$ Electronic supplementary information (ESI) available: Calculated and experimental values of selected NMR parameters for fluoromethanes (Tables S1-S4), 1,1,2-trifluoro-2-methylcyclopropane (Table S5) and for 7-fluoronorbornane derivatives (Table S6). See DOI: 10.1039/c6ra15343g soman) or their components. At the same time, fluorocompounds are very interesting objects for NMR investigations owing to $100 \%$ natural abundance of ${ }^{19} \mathrm{~F}$ isotope, the nucleus of which possesses $1 / 2$ spin and high magnetic moment. These features cause that fluorine nucleus present in the molecule is a very convenient probe, useful in structural studies of fluorocompounds. ${ }^{5-12}$ Thus, the chemistry of fluorinecontaining compounds is an important branch of chemistry and, simultaneously, NMR of such compounds is an interesting and important part of NMR spectroscopy.

It is thus obvious that it would be desirable to have theoretical methods of predicting NMR parameters, whose effectiveness would be well-checked for fluorocompounds. Actually, it has been shown that NMR parameters can be successfully calculated for small fluorine-containing molecules using the high level $a b$ initio post-Hartree-Fock methods. ${ }^{13-19}$ Unfortunately, those methods are inefficient, due to practical reasons, even for the medium size molecules. For example, some difficulties already arose during application of such a method to $\mathrm{CHF}_{3}$ molecule. $^{\mathbf{1 3}}$ It is true that computer techniques are continuously developing, but on the other hand, it is clear that high level theoretical methods are not a real way out. A good practical solution would be elaboration of a suitable DFT-based method. Such methods are presently standard in calculations of NMR parameters for organic compounds composed of $\mathrm{C}, \mathrm{H}, \mathrm{N}$, 
$\mathrm{O}$ and some other atoms. ${ }^{\mathbf{2 0 - 2 6}}$ Even when molecule contains heavier atoms, good results can be obtained using DFT methods provided that relativistic effects are included into the theoretical model. ${ }^{25,27-29}$ It has been shown that also for fluoroorganic compounds the magnetic shielding of carbon and fluorine nuclei can be calculated with an acceptable accuracy by more or less standard DFT methods. ${ }^{\mathbf{1 8 2 2 , 3 0 - 3 3}}$ The problem of predicting ${ }^{19} \mathrm{~F}$ chemical shifts has recently been tested in detail on the large body of experimental data. ${ }^{33,34}$ On the other hand, the first test calculations of the indirect spin-spin coupling constants in such compounds yielded definitely poor values of ${ }^{1} J(\mathrm{~F}, \mathrm{C})$ parameter. ${ }^{35}$ It has also been noticed that the same problem concerns two-bond indirect spin-spin coupling constants between geminal fluorines. ${ }^{15}$ Below we show some more examples illustrating such problems. Let us remind, however, that already 20 years ago the hope was expressed that after construction of suitable functionals the DFT should work properly and that large divergences between theory and experiment would be eliminated also in the case of NMR parameters of fluorine compounds. ${ }^{35}$ Indeed, in recent years it has been shown that values of one-bond fluorine-carbon spin-spin coupling constants can be predicted quite well when using the BHandH functional, ${ }^{36,37}$ already known for a long time. To the best of our knowledge, however, most hitherto examples showing the effectiveness of this method concern molecules in which fluorine is bonded to $\mathrm{sp}^{2}$ hybridized carbons. ${ }^{\mathbf{1 1}, \mathbf{1 2}, \mathbf{1 8 , 3 8 , 3 9}}$ Also some interesting theoretical papers concerning calculations of various fluorine-fluorine coupling constants, including ${ }^{2} J(\mathrm{~F}, \mathrm{~F})$ constant, have appeared in recent years. ${ }^{\mathbf{1 8 , 4 0}}$ Results reported in this work show that also for fluoroalkanes and fluorocycloalkanes good values of ${ }^{1} J(\mathrm{~F}, \mathrm{C})$ spin-spin coupling constants are obtained when using $\mathrm{BHandH}$ functional. This approach appears to be effective also in the case of some other fluorine-X $(\mathrm{X}=\mathrm{H}, \mathrm{C}, \mathrm{F})$ coupling constants, including the difficult ${ }^{2} J(\mathrm{~F}, \mathrm{~F})$ case.

\section{Calculations}

Looking for an efficient and practicable theoretical method of calculating the values of nuclear indirect spin-spin coupling constants involving fluorine nuclei for aliphatic fluorocompounds, we have performed several test DFT calculations for the series of fluoromethanes and fluoroethanes. On the basis of the obtained results some tentative recommendations concerning the choice of theoretical methods suitable for such calculations could be formulated. The effectiveness of the selected methods has been then verified by applying them in calculations of NMR parameters for several larger objects. Taking into account some literature hints and also our earlier results we have decided to test the effectiveness of three hybrid functionals: B3LYP, ${ }^{41}$ PBE0 (BPE1BPE in Gaussian 03) ${ }^{42}$ and BHandH. ${ }^{36,37}$ The two first functionals are very popular in NMR calculations ${ }^{20,24,25,43,44}$ and the third was shown to yield the best values of one-bond fluorine-carbon spin-spin coupling constants for fluoroaromatics. ${ }^{11,12,18,39}$ In our calculations we have used three basis sets: 6-311++G(2d,p), 6-311++G(3df,3pd) and aug-pcJ-3-2006 abbreviated from here on: s, $m$ and 1 , respectively. The first two basis sets are of moderate size and more or less standard for NMR calculations, ${ }^{\mathbf{2 0 , 2 4 , 2 5}}$ whereas the third basis has been dedicated especially to calculations of the spin-spin coupling constants. ${ }^{45}$ It would be the most comfortable situation if a universal and relatively small basis set appears effective for NMR calculations, although some Jdedicated basis can also be considered. The problem with good bases of this type is that they are usually much larger than $\mathrm{s}$ basis, sufficient in most magnetic shielding calculations. Nevertheless, if the quality of the prediction were substantially better thanks to such larger basis (or perhaps appropriate locally-dense bases), the method would indeed be useful. That is why we performed some calculations with 1 basis, too.

It is a common knowledge that the values of NMR parameters obtained in calculation are highly dependent on the molecular geometry introduced in the input data. Most frequently, the calculations is performed for the theoretical minimum-energy molecular structures and the molecular geometry optimization is the first step of the whole calculation..$^{\mathbf{2 0 2 4 , 2 5}}$ In the primary tests performed in this work the same functional and basis set have been used during both calculation steps (molecular geometry optimization and NMR parameters computation). For fluoromethanes the calculations have been performed using all the combinations of three mentioned functionals and three basis sets.

The experimental NMR data, needed to evaluate the results of our calculations, have been taken from different literature sources. ${ }^{\mathbf{8 , 1 3 , 3 0 , 3 1 , 4 6 - 5 9}}$ In most of these sources only the absolute values of the indirect spin-spin coupling constants have been determined. Throughout this work the signs of these constants have been assumed to be the same as those of calculated values. Unfortunately, the high precision gas phase NMR data are available only for three fluoromethanes. ${ }^{\mathbf{1 3 , 5 5 - 5 7}}$ NMR spectra for other compounds of interest were measured in various solvents (from $\mathrm{CCl}_{4}$ to methanol- $\mathrm{d}_{4}$ ). In such a situation, in order to compensate, at least partially, for medium effects, most of our calculations have been performed using polarizable continuum model of the solvent $(\mathrm{PCM})^{60}$ with the set of atomic radii collected in the Gaussian software under the keyword "radii = UAKS".36

All quantum chemical calculations were performed using GAUSSIAN 03 software, ${ }^{61}$ which was also the source of functionals as well as $\mathrm{s}$ and $\mathrm{m}$ basis sets. ${ }^{36,37}$ The basis set $\mathrm{l}$ was taken from ref. 45 .

\section{Results and discussion}

\section{An unexpected success}

For a long time a simple HF molecule have been considered to be a troublesome case. In a fundamental work in which Tozer et al. $^{\mathbf{4 4}}$ tested performance of various exchange-correlation functionals in predicting values of indirect nuclear spin-spin coupling constants, the authors decided to "omit the challenging HF molecule from the analysis". The reason was that as opposite to the other molecules tested, in the case of HF, the calculated ${ }^{1} J(\mathrm{~F}, \mathrm{H})$ values were not satisfying, independently of the DFT method used. Indeed, the calculated value was at best 
458.0 Hz, while the experimental one was $538.0 \mathrm{~Hz} .^{62}$ Prompted by the encouraging results in predicting ${ }^{1} J(\mathrm{~F}, \mathrm{C})$ in aromatic fluorocompounds by DFT methods when using BHandH functional we have optimized the HF molecular geometry using $\mathrm{BHandH} / \mathrm{s}$ method and then calculated ${ }^{1} J(\mathrm{~F}, \mathrm{H})$ coupling constant for this molecule using the same functional and $\mathrm{s}$ and $\mathrm{l}$ bases. The results have been $469.2 \mathrm{~Hz}$ and $543.3 \mathrm{~Hz}$, respectively. Such an excellent result is probably an effect of error cancellation. Even if it is so, it will be worth knowing how frequently such error cancellations occur when calculating ${ }^{n} J(\mathrm{~F}, \mathrm{X})$ parameters.

\section{The simplest objects}

Looking for an effective DFT method of calculating nuclear spin-spin coupling constants for aliphatic fluorocompounds we have first performed several test calculations of NMR parameters for the series of fluoromethanes and four fluoroethanes $\left(\mathrm{CH}_{2} \mathrm{FCH}_{3}, \mathrm{CHF}_{2} \mathrm{CH}_{3}, \mathrm{CF}_{3} \mathrm{CH}_{3}\right.$ and $\left.\mathrm{CF}_{3} \mathrm{CH}_{2} \mathrm{~F}\right)$. These objects were selected for two obvious reasons: the simplicity of their molecular structures and the accessibility of the precise experimental NMR data for them.

Fluoromethanes are the simplest fluoroalkanes and possess rigid structures. Let us note, too, that the molecules of the chosen fluoroethanes contain either methyl or trifluoromethyl group. Owing to the symmetry of these groups, the three staggered conformers of these compounds have identical equilibrium molecular geometry and so are equally populated at any temperature. Moreover, at temperatures normally used in liquid state NMR measurements the internal rotation about $\mathrm{C}-\mathrm{C}$ bonds in these molecules is rapid and averages out the magnetic environments of three protons (or fluorines) as well as appropriate NMR parameters. This feature simplifies the structures of NMR spectra and makes the comparison of the experimentally obtained and calculated values of NMR parameters much easier.

As it concerns the experimental data for $\mathrm{CH}_{3} \mathrm{~F}, \mathrm{CH}_{2} \mathrm{~F}_{2}$ and $\mathrm{CHF}_{3}$, they have been measured in gaseous state and extrapolated to zero-density. .3,55-57 $^{\text {For tetrafluoromethane }}{ }^{31}$ and selected fluoroethanes ${ }^{\mathbf{8 , 3 1 , 4 7 , 4 8}}$ only the solution data are available. Fortunately, for molecules whose structures (including conformation) are solvent independent, the spin-spin coupling constants are also poorly solvent dependent. Nevertheless, as it was mentioned, in order to compensate for these small medium effects the polarizable continuum solvent model $(\mathrm{PCM})^{\mathbf{6 0}}$ has been used in our calculations. Still, when comparing such theoretical data with experimental ones, the inherent limitations of the PCM method have to be kept in mind.

The values of the isotropic indirect spin-spin coupling constants calculated for fluoromethanes are collected in Table 1. These values have been obtained with the aid of 9 theoretical methods in which the same functional/basis pair has been used at both calculation steps. The table also contains the values of these parameters determined experimentally as well as some high-level $a b$ initio theoretical data. Since it is believed that the gas phase molecular geometries are usually very well reproduced already when using the $\mathrm{s}$ basis, the smallest one we have used, we additionally performed some test NMR calculations using such geometries independently of the basis used in the second step of computation. Indeed, the differences between the results obtained this way and by the more time consuming methods mentioned above were usually small, although not always negligible.

Similar data for the selected fluoroethanes are collected in Table 2 . The table contains the data concerning only these $J(\mathrm{~F}, \mathrm{X})$ $\left[\right.$ or $\left.^{1} J(\mathrm{C}, \mathrm{H})\right]$ coupling constants the experimental values of which are available in the cited literature sources. Some additional calculated and experimental values of NMR parameters for

Table 1 The experimental and theoretically predicted values of the indirect spin-spin coupling constants [Hz] for fluoromethanes. The molecular geometry optimization and NMR parameter calculations were performed using the same DFT method

Method

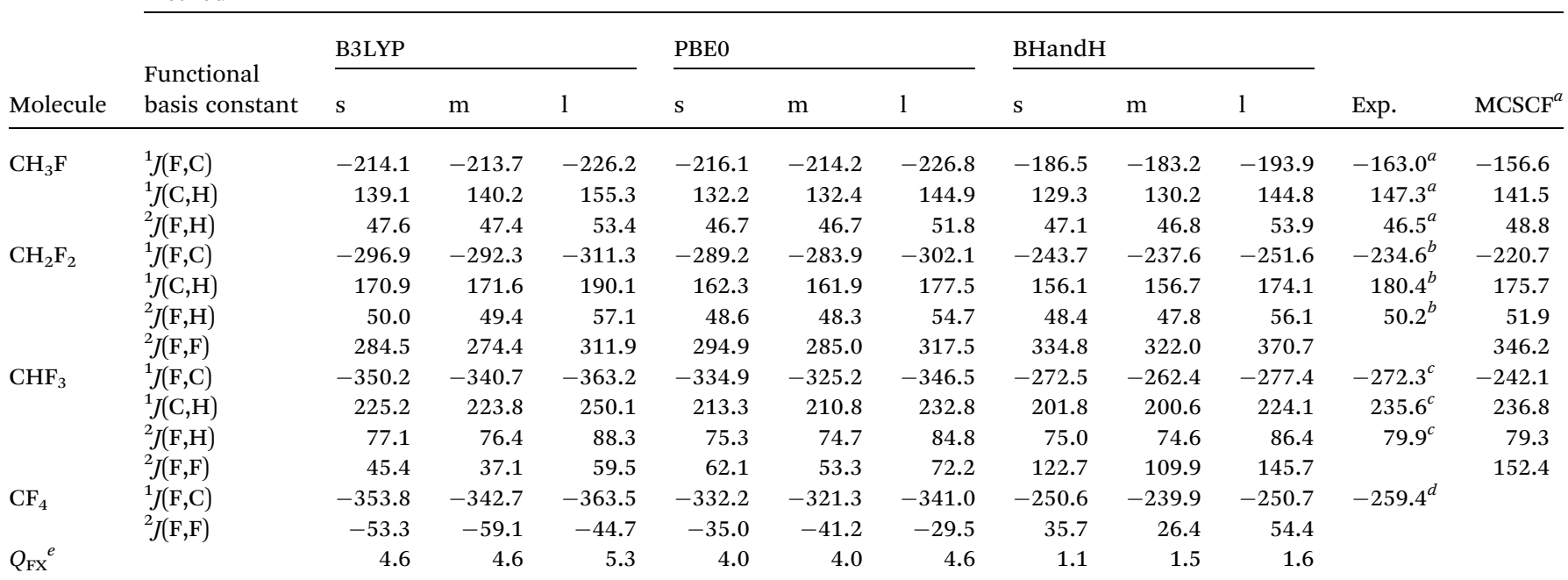

${ }^{a}$ Ref. $13 .{ }^{b}$ Ref. 57. ${ }^{c}$ Ref. $56 .{ }^{d}$ Ref. $46 .{ }^{e}$ The averaged value of the prediction-quality indicator of $J(\mathrm{~F}, \mathrm{X})$ parameters for a given theoretical method. 
Table 2 The experimental and theoretically predicted values of the selected indirect spin-spin coupling constants (in $\mathrm{Hz}$ ) for a few fluoroethanes

\begin{tabular}{llrrrr}
\hline Molecule & Constant & B3LYP/s & PBE0/l & BHandH/s & \multicolumn{1}{c}{ Exp. } \\
\hline $\mathrm{CH}_{2} \mathrm{FCH}_{3}$ & ${ }^{1} J(\mathrm{~F}, \mathrm{C})$ & -201.3 & -216.8 & -174.5 & $160.6^{b}$ \\
& ${ }^{b} J(\mathrm{~F}, \mathrm{C})$ & 15.8 & 20.4 & 19.6 & $20.7^{b}$ \\
& ${ }^{2} J(\mathrm{~F}, \mathrm{H})$ & 49.5 & 53.0 & 47.5 & $47.1^{b}$ \\
& ${ }^{3} J(\mathrm{~F}, \mathrm{H})$ & 23.2 & 26.3 & 26.2 & $26.4^{b}$ \\
$\mathrm{CHF}_{2} \mathrm{CH}_{3}$ & ${ }^{1} J(\mathrm{~F}, \mathrm{C})$ & -288.1 & -294.5 & -233.4 & $-233.5^{c}$ \\
& ${ }^{2} J(\mathrm{~F}, \mathrm{C})$ & 17.4 & 22.3 & 21.4 & $22.5^{c}$ \\
& $1 J(\mathrm{C}-1, \mathrm{H})$ & 176.1 & 181.1 & 159.0 & $187.9^{c}$ \\
& ${ }^{1} J(\mathrm{C}-2, \mathrm{H})$ & 122.2 & 126.5 & 113.7 & $127.9^{c}$ \\
$\mathrm{CF}_{3} \mathrm{CH}_{3}$ & ${ }^{j} J(\mathrm{~F}, \mathrm{C})$ & -343.2 & -337.9 & -259.5 & $-273.0^{b}$ \\
& ${ }^{2} J(\mathrm{~F}, \mathrm{C})$ & 27.8 & 32.8 & 32.1 & $31.5^{b}$ \\
& ${ }^{3} J(\mathrm{~F}, \mathrm{H})$ & 10.2 & 12.2 & 12.4 & $12.9^{b}$ \\
$\mathrm{CF}_{3} \mathrm{CH}_{2} \mathrm{~F}$ & ${ }^{b} J(\mathrm{~F}, \mathrm{H})$ & 47.7 & 51.7 & 46.3 & $45.9^{d}$ \\
& ${ }^{3} J(\mathrm{~F}, \mathrm{H})$ & 6.0 & 7.3 & 7.4 & $7.9^{d}$ \\
& ${ }^{3} J(\mathrm{~F}, \mathrm{~F})$ & -23.4 & -22.3 & -21.1 & $-16.1^{d}$ \\
$Q_{\mathrm{FX}}{ }^{e}$ & & 3.7 & 3.2 & 0.9 &
\end{tabular}

${ }^{a}$ In this case the molecular geometry was optimized using DFT PBE0/m PCM(solvent) method. ${ }^{b}$ Ref. $47 .^{c}$ Ref. $49 .{ }^{d}$ Ref. $8 .{ }^{e}$ The averaged value of the prediction-quality indicator for various $J(\mathrm{~F}, \mathrm{X})$ parameters, including the data for fluoromethanes (Table 1).

fluoromethanes, fluoroethanes discussed in this work can be found in the ESI (Tables S1-S4†).

\section{Prediction-quality criterion}

Before we formulate a final recommendation concerning theoretical calculations of NMR parameters, being of interest in this study, it seems desirable to assume a criterion allowing the quality of a theoretical prediction to be expressed in a more or less objective way. This seemingly trivial question is not such, actually, when the substantial amount of data obtained by various methods and results concerning various types of coupling constants are to be compared. It is obvious that, say, 5 $\mathrm{Hz}$ difference between theoretical and experimental value denotes definitely poor prediction in the case of a vicinal coupling constant and an excellent prediction of one-bond ${ }^{19} \mathrm{~F}-{ }^{13} \mathrm{C}$ coupling constant. Again, the relative error is not an adequate criterion for small coupling constants. Moreover, it has to be taken into account that the available experimental values are of very different precision. The values of fluorinecarbon coupling constants, for example, happen to be read out directly from the spectrum and reported as spectral line separations (without line-shape analysis). ${ }^{47,50,53}$ The error of such data can be of the order of the linewidth or higher. Taking all these arguments into account we have assumed for coupling constants expressed in $\mathrm{Hz}$ the prediction-quality indicator as:

$$
Q=\left|J_{\exp }-J_{\text {calc }}\right| /\left(0.5+0.05 \times\left|J_{\exp }\right|\right)
$$

The good quality prediction will denote from here on $C \leq 1$, and poor prediction $C \geq 3$.

Eventually, it is obvious that the size of the basis set determines the computer time needed to complete the calculation. Frequently, just the size of the basis set required for getting reliable results decides whether the proposed method is useful for molecules being of interest to chemists, or not. For instance, calculation of NMR parameters for trifluoromethane (without molecular geometry optimization) demanded 4 minutes, 15 minutes and almost 15 hours of the nominal computer time, when using B3LYP functional and the three basis sets mentioned above. It is worth keeping in mind these numbers when comparing the effectiveness of particular calculation methods.

\section{Valuation of the results for fluoromethanes and fluoroethanes}

Application of the prediction-quality indicator (eqn (1)) to the data of Tables 1 and 2 immediately shows that in most cases the values of spin-spin coupling constants involving fluorine nuclei can be successfully predicted using the $\mathrm{BHand} / \mathrm{H}$ s method (the last entries in Tables 1-3). It is noteworthy that for $\mathrm{CH}_{3} \mathrm{~F}, \mathrm{CH}_{2} \mathrm{~F}_{2}$ and $\mathrm{CHF}_{3}$ these DFT results are as good as or better than those obtained by high level $a b$ initio calculations (Table 1$) \cdot{ }^{13}$ Especially in the case of ${ }^{1} J(\mathrm{~F}, \mathrm{C})$ coupling constants the prevalence of $\mathrm{BHandH} / \mathrm{s}$ calculation method over other methods tested is well visible (Table 3). For this method, only in the case of fluoromethane, a remarkable $23.5 \mathrm{~Hz}$ difference between calculated and experimental results is observed. Nevertheless, this deviation is still smaller than any one obtained by methods using other tested functionals, and still represents only $14 \%$ of the

Table 3 Comparison of the effectiveness of three DFT methods in predicting values of various types of spin-spin coupling constants for fluoromethanes and fluoroethanes. $\left[Q_{\mathrm{av}}\right.$ - the averaged value of the prediction-quality indicator (eqn (1)), $n$ - the number of experimental values of a given type of coupling constant, $n_{w}, n_{m}$ and $n_{p}$ - number of values predicted well $(Q \leq 1)$, moderately well $(1<Q<3)$ and poorly $(Q$ $\geq 3$ ), respectively]

\begin{tabular}{|c|c|c|c|c|c|c|}
\hline Coupling constant & $n$ & Method & $n_{\mathrm{w}}$ & $n_{\mathrm{m}}$ & $n_{\mathrm{p}}$ & $Q_{\mathrm{av}}$ \\
\hline \multirow[t]{3}{*}{${ }^{1} J(\mathrm{~F}, \mathrm{C})$} & \multirow[t]{3}{*}{7} & B3LYP/s & 0 & 0 & 7 & 5.7 \\
\hline & & PBE0/1 & 0 & 0 & 7 & 5.8 \\
\hline & & BHandH/s & 5 & 2 & 0 & 1.0 \\
\hline \multirow[t]{3}{*}{${ }^{2} J(\mathrm{~F}, \mathrm{H})$} & \multirow[t]{3}{*}{5} & B3LYP/s & 5 & 0 & 0 & 0.5 \\
\hline & & PBE0/1 & 0 & 5 & 0 & 1.7 \\
\hline & & BHandH/s & 4 & 1 & 0 & 0.4 \\
\hline \multirow[t]{3}{*}{${ }^{2} J(\mathrm{~F}, \mathrm{C})$} & \multirow[t]{3}{*}{3} & B3LYP/s & 0 & 1 & 2 & 2.7 \\
\hline & & PBE0/1 & 3 & 0 & 0 & 0.3 \\
\hline & & BHandH/s & 3 & 0 & 0 & 0.6 \\
\hline \multirow[t]{3}{*}{${ }^{2} J(\mathrm{~F}, \mathrm{~F})$} & \multirow[t]{3}{*}{2} & B3LYP/s & 0 & 0 & 2 & 8.3 \\
\hline & & PBE0/1 & 0 & 1 & 1 & 5.7 \\
\hline & & BHandH/s & 1 & 0 & 1 & 2.1 \\
\hline \multirow[t]{3}{*}{${ }^{3} J(\mathrm{~F}, \mathrm{H})$} & \multirow[t]{3}{*}{3} & B3LYP/s & 0 & 3 & 0 & 2.1 \\
\hline & & PBE0/1 & 3 & 0 & 0 & 0.4 \\
\hline & & BHandH/s & 3 & 0 & 0 & 0.4 \\
\hline \multirow[t]{3}{*}{${ }^{3} J(\mathrm{~F}, \mathrm{~F})$} & \multirow[t]{3}{*}{1} & $\mathrm{~B} 3 \mathrm{LYP} / \mathrm{s}$ & 0 & 0 & 1 & 5.6 \\
\hline & & PBE0/1 & 0 & 0 & 1 & 4.8 \\
\hline & & BHandH/s & 0 & 0 & 1 & 3.8 \\
\hline \multirow[t]{3}{*}{${ }^{1} J(\mathrm{C}, \mathrm{H})^{a}$} & \multirow[t]{3}{*}{8} & B3LYP/s & 6 & 2 & 0 & 0.9 \\
\hline & & PBE0/1 & 8 & 0 & 0 & 0.3 \\
\hline & & BHandH/s & 0 & 8 & 0 & 2.3 \\
\hline
\end{tabular}

${ }^{a}$ In this case the data for 1,1-difluoro-2-chlorocyclopropane (Table 5) have also been included. 
experimental parameter value $(Q=2.7)$. The predictions of all other ${ }^{1} J(\mathrm{~F}, \mathrm{C})$ values by the BHandH/s method are good, whereas methods using two other functionals have yielded remarkably poorer results. We will show that similar situation occurs for ${ }^{2} J(\mathrm{~F}, \mathrm{~F})$ coupling constants, although at the moment we have had at our disposal only two ab initio results, ${ }^{13}$ which could be confronted with the results of our calculations. The results concerning other types of $J(\mathrm{~F}, \mathrm{X})$ constants in fluoromethanes and fluoroethanes are also encouraging (Table 3), however, some types of coupling constants are poorly represented in the data set of Tables 1 and 2 and so conclusions concerning effectiveness of the BHandH/s method in those cases will be verified below.

\section{1,2-Difluoroethane}

It has been mentioned that non-rigidity of molecules of fluoroethanes possessing methyl or trifluoromethyl group simplifies a comparison of the results of NMR measurements and theoretical calculations. The molecule of 1,2-difluoroethane, however, represents quite a different case. The antiperiplanar (trans) minimum-energy conformer of this compound differs from two enantiomeric synclinal (gauche) conformers. The populations of trans and gauche conformers are different and are temperature and solvent dependent. The molecule of 1,2-difluoroethane has been investigated many times in the past both experimentally and theoretically. ${ }^{8,63-65}$ It has been proven that this compound demonstrates the rare case of a high prevalence of the synclinal conformers over the antiperiplanar one ${ }^{8,63-65}$ We have concluded that it could be interesting whether the values of spin-spin coupling constants calculated by BHandH/s method confirm this finding. Table 4 contains the results of our calculations performed for both types of conformers of this molecule. More precisely, the values calculated for antiperiplanar conformer and mean values of those calculated for two synclinal conformers are given in the table. First of all, one can notice that three of four vicinal spinspin coupling constants are strongly conformation dependent. Comparing them with the appropriate experimental data clearly shows that the values of coupling constants calculated for

Table 4 Comparison of the theoretically predicted values of spinspin coupling constants for two conformers of 1,2-difluoroethane in $\mathrm{CH}_{2} \mathrm{Cl}_{2}$ and $\mathrm{C}_{6} \mathrm{H}_{12}$ with the experimental values of these parameters

\begin{tabular}{|c|c|c|c|c|c|c|}
\hline Constant & ${ }^{2} J(\mathrm{~F}, \mathrm{H})$ & ${ }^{3} J(\mathrm{~F}, \mathrm{H})$ & ${ }^{2} J(\mathrm{H}, \mathrm{H})$ & ${ }^{3} J(\mathrm{H}, \mathrm{H})$ & ${ }^{3} J(\mathrm{H}, \mathrm{H})$ & ${ }^{3} J(\mathrm{~F}, \mathrm{~F})$ \\
\hline \multicolumn{7}{|c|}{ BHandH/s PCM($\left(\mathrm{CH}_{2} \mathrm{Cl}_{2}\right)$} \\
\hline Gauche $^{a}$ & 48.7 & 31.5 & -12.1 & 5.5 & 1.5 & -12.4 \\
\hline trans & 45.5 & 1.4 & -8.7 & 6.1 & 10.8 & -45.4 \\
\hline Exp. $^{b}$ & 47.9 & 30.8 & -11.8 & 5.7 & 1.5 & -10.7 \\
\hline \multicolumn{7}{|c|}{ BHandH/s PCM $\left(\mathrm{C}_{6} \mathrm{H}_{12}\right)$} \\
\hline Gauche ${ }^{a}$ & 48.6 & 30.9 & -11.9 & 5.5 & 1.4 & -12.4 \\
\hline trans & 45.7 & 1.4 & -8.7 & 6.1 & 10.7 & -47.9 \\
\hline Exp. $^{b}$ & 47.5 & 28.6 & -11.2 & 5.6 & 1.8 & -11.6 \\
\hline
\end{tabular}

${ }^{a}$ The values averaged by a virtual exchange between two synclinal (enantiomeric) optimum energy conformers. ${ }^{b}$ Ref. 8. gauche conformations are close to the experimental ones. Our results thus remain in full agreement with the earlier findings concerning equilibrium conformation of this molecule.

It is perhaps noteworthy that the achieved agreement between calculated and experimental values of the indirect spinspin coupling constants for all fluoroethanes is actually better than expected. As usual, all calculations have been done for equilibrium geometries of minimum-energy conformations. It is obvious, however, that the structure of all fluoroethanes is not rigid, the barriers to internal rotations are low and even in the ground vibrational state molecules librate around equilibrium geometry. Moreover, at room temperature probably the higher vibrational states of these modes are populated. There is no guarantee that averaging of the spin-spin coupling constants by librations yields the same values as those for the equilibrium geometry. Neglect of these internal motions during NMR parameters calculation is probably an oversimplification. ${ }^{66} \mathrm{~A}$ much more sophisticated treatment of this problem, such as that developed by Schaefer, ${ }^{66}$ would probably be more adequate.

\section{Further objects}

In order to test further the effectiveness of the selected theoretical method we have included into the analyzed data set the spin-spin coupling constants for two rather non-standard fluorinated alkanes, namely, 1,1-difluoro-2-chlorocyclopropane and 1,1,2-trifluoro-2-methylcyclopropane. A large number of spin-spin coupling constants for these compounds have been reported by Brey. ${ }^{50,53}$ We have found out that also in this case the values of most of the reported coupling constants have been reproduced well when the BHandH/s method is used (Tables 5 and $\mathrm{S} 5 \dagger$ ).

The selected theoretical methods have also been applied to calculate NMR parameters for axial and equatorial conformers of fluorocyclohexane investigated at low temperatures and five fluorinated norbornane derivatives. These seven objects have been interesting from our point of view due to their rigid structures. In this case, the reliability of our results could be verified by confronting them with the experimental data reported by Abraham et al. ${ }^{47,59}$ The results of our calculations of the indirect ${ }^{19} \mathrm{~F}^{13} \mathrm{C}$ spin-spin coupling constants for these molecules and the reported experimental values of these parameters are collected in Tables 6 and S6. $\uparrow$ Again, the agreement between calculated and experimental values, in general, is good.

Our collection of the experimental coupling constant data has contained until now only three two-bond coupling constants involving geminal fluorines, those in cyclopropanes and 2,2-difluoronorbornane. In order to get more data for experiment/theory comparison we have performed calculations for a few other molecules possessing $-\mathrm{CF}_{2^{-}}$fragment: 5,5difluoro-1,3-dioxane, whose spectrum was recorded at very low temperature, ${ }^{54}$ 1,1-difluoro-3-methylcyclohexane which is expected to occur in solutions mostly as a conformer with the methyl substituent occupying the equatorial position ${ }^{47} 2,2-$ difluoro-cis-3-methylcyclopentanol ${ }^{51}$ and 3,3-difluoro-5-methylcyclopentene..$^{52}$ Three of these compounds probably occur in 
Table 5 Comparison of calculated and experimental ${ }^{a}$ values of selected spin-spin coupling constants for 1,1-difluoro-2-chlorocyclopropane in acetone solution ${ }^{b}$

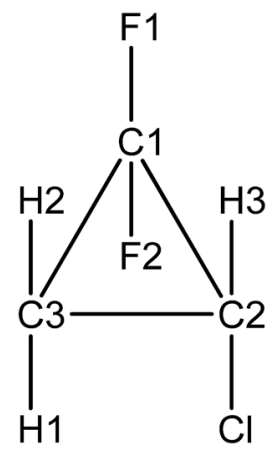

\begin{tabular}{lrrrr}
\hline Constant & B3LYP/s & PBE0/l & BHandH/s & \multicolumn{1}{c}{ Exp. } \\
\hline${ }^{2} J(\mathrm{~F}-1, \mathrm{~F}-2)$ & 86.3 & 117.4 & 151.3 & 158.9 \\
${ }^{1} J(\mathrm{~F}-2, \mathrm{C}-1)$ & -358.0 & -351.7 & -268.5 & -284.1 \\
${ }_{1}^{1} J(\mathrm{~F}-1, \mathrm{C}-1)$ & -364.3 & -359.1 & -275.4 & -289.8 \\
${ }^{2} J(\mathrm{~F}-2, \mathrm{C}-2)$ & 6.6 & 9.4 & 8.9 & 11.3 \\
${ }^{2} J(\mathrm{~F}-1, \mathrm{C}-2)$ & 7.4 & 12.4 & 12.8 & 15.3 \\
${ }^{2} J(\mathrm{~F}-2, \mathrm{C}-3)$ & 5.1 & 8.6 & 8.5 & 10.7 \\
${ }^{2} J(\mathrm{~F}-1, \mathrm{C}-3)$ & 6.6 & 9.2 & 8.9 & 11.5 \\
${ }^{3} J(\mathrm{~F}-2, \mathrm{H}-3)$ & -3.9 & -3.2 & -3.7 & -1.9 \\
${ }^{3} J(\mathrm{~F}-1, \mathrm{H}-3)$ & 10.7 & 11.6 & 12.2 & 11.0 \\
${ }^{3} J(\mathrm{~F}-2, \mathrm{H}-1)$ & 12.0 & 13.5 & 14.2 & 13.4 \\
${ }^{3} J(\mathrm{~F}-1, \mathrm{H}-1)$ & 1.1 & 2.9 & 2.5 & 4.6 \\
${ }^{3} J(\mathrm{~F}-2, \mathrm{H}-2)$ & 2.8 & 5.1 & 4.3 & 6.4 \\
${ }^{3} J(\mathrm{~F}-1, \mathrm{H}-2)$ & 11.7 & 13.4 & 13.7 & 13.7 \\
${ }_{1}^{1} J(\mathrm{C}-2, \mathrm{H}-3)$ & 185.4 & 190.5 & 173.0 & 192.8 \\
${ }^{1} J(\mathrm{C}-3, \mathrm{H}-2)$ & 160.1 & 165.8 & 150.0 & 166.4 \\
${ }^{1} J(\mathrm{C}-3, \mathrm{H}-1)$ & 159.3 & 163.9 & 148.7 & 164.7
\end{tabular}

${ }^{a}$ As reported in ref. 50, adopting signs being in accord with calculated values. ${ }^{b}$ Molecular geometry optimization calculated by PBE0/m. solution in measurement conditions as equilibrium conformer mixtures. Calculations show, however, that the ${ }^{2} J(\mathrm{~F}, \mathrm{~F})$ parameter is poorly conformation-dependent. This observation is in accord with the finding of Tormena et al. ${ }^{67}$ who have shown that in $\mathrm{CF}_{2}$ group the geminal $\mathrm{F}-\mathrm{F}$ coupling constant depends mainly on the angle between $\mathrm{C}-\mathrm{F}$ bonds involved.

\section{Verification of the selected method}

Finally, all the data collected during this work have been subjected to the prediction-effectiveness test using the proposed criterion (eqn (1)). The results of this analysis are summarized in Table 7 and graphically presented in Fig. 1 and S1. $\dagger$ They confirm that there are at least two cases in which theoretical predictions of the values of spin-spin coupling constants involving fluorine nucleus by DFT methods commonly used for calculating NMR parameters yield results biased by unacceptably large errors. These troublesome parameters are ${ }^{1} J(\mathrm{~F}, \mathrm{C})$ and ${ }^{2} J(\mathrm{~F}, \mathrm{~F}) .{ }^{15,17,35}$ The first entry of Table 7 shows that application of the DFT BHandH/s method does solve this problem in the case of one-bond ${ }^{19} \mathrm{~F}^{13} \mathrm{C}$ coupling constants involving the aliphaticcarbon-bound fluorines $\left(Q_{\mathrm{av}}=0.9\right)$. Let us remind that in recent years it has been shown that this method worked well also for fluorines bonded to aromatic carbons. ${ }^{11,12,18,38,39}$ Our calculations additionally show, which is even more novel, that this DFT method solves a similar problem occurring in the case of a twobond coupling involving geminal fluorines. We have found out that, without exception, the recommended DFT BHandH/s method reproduces experimental results well $\left(Q_{\mathrm{av}}=0.6\right)$, much better than the method which uses the B3LYP functional $\left(Q_{\mathrm{av}}=6.2\right)$. Since, overall, quite a lot of experimental and theoretical data have been compared we may conclude that the effectiveness of the DFT BHandH/s method in predicting ${ }^{1} J(\mathrm{~F}, \mathrm{C})$ and ${ }^{2} J(\mathrm{~F}, \mathrm{~F})$ values is well-verified. Moreover, it has been noticed that in every case the differences between theoretical parameter

Table 6 Comparison of the experimentally determined fluorine-carbon spin-spin coupling constants (from ref. 47) for two conformers of fluorocyclohexane, 1,1-difluoro-3-methylcyclohexane and 2,2-difluoronorbornane with the values of these parameters calculated using $\mathrm{BHandH} / \mathrm{s}$ (PCM) method. Superscripts: eq - equatorial, ax - axial, en - endo and ex - exo inform about the stereochemical position occupied by a given fluorine substituent

Two conformers of fluorocyclohexane

\begin{tabular}{lrrrrrrrr}
\hline $\mathrm{C}$ & $\mathrm{F}^{\mathrm{ax}}$ & Exp. $^{\text {ax }}$ & \multicolumn{1}{c}{$\mathrm{F}^{\mathrm{eq}}$} & Exp. $^{\text {eq }}$ & $\mathrm{C}$ & $\mathrm{F}^{\mathrm{ax}}$ & Exp. $^{\text {ax }}$ & $\mathrm{F}^{\mathrm{eq}}$ \\
\hline $\mathrm{C}-1$ & -168.1 & -165.5 & -175.5 & -170.4 & $\mathrm{C}-3$ & 2.0 & 0.0 & 10.8 \\
$\mathrm{C}-2$ & 20.1 & 21.3 & 17.5 & 17.2 & $\mathrm{C}-4$ & -0.4 & 0.0 & -2.5 \\
\hline
\end{tabular}

1,1-Difluoro-3-methylcyclohexane

2,2-Difluoronorbornane

\begin{tabular}{|c|c|c|c|c|c|c|c|}
\hline $\mathrm{C}$ & $\mathrm{F}^{\mathrm{ax}}$ & $\mathrm{F}^{\mathrm{eq}}$ & Exp. & $\mathrm{C}$ & $\mathrm{F}^{\mathrm{en}}$ & $\mathrm{F}^{\mathrm{ex}}$ & Exp. \\
\hline C-1 & -224.8 & -233.2 & $-238.7,-242.2$ & C-1 & 21.2 & 24.2 & $21.3,23.6$ \\
\hline $\mathrm{C}-2$ & 24.3 & 20.9 & $25.1,20.4$ & $\mathrm{C}-2$ & -240.4 & -238.6 & $-255.6,-251.7$ \\
\hline C-4 & -0.4 & -2.2 & $0,2.0$ & C-4 & 4.2 & 2.3 & $4.3,2.2$ \\
\hline C-5 & 0.3 & 9.3 & $0,9.7$ & C-5 & -0.4 & 1.1 & 0,0 \\
\hline C-6 & 24.7 & 22.3 & $25.5,22.2$ & C-6 & 7.5 & 5.1 & $6.0,6.0$ \\
\hline
\end{tabular}


Table 7 Comparison of the effectiveness of B3LYP/s and BHandH/s DFT methods in predicting values of various types of spin-spin coupling constants involving ${ }^{19} \mathrm{~F}$ nucleus. $\left[Q_{\mathrm{av}}\right.$ - the averaged value of the prediction-quality indicator (eqn (1)), $n$ - the number of experimental values of a given type of coupling constant, $n_{\mathrm{w}}, n_{\mathrm{m}}$ and $n_{\mathrm{p}}-$ number of values predicted well $(Q \leq 1)$, moderately well $(1<Q<3)$ and poorly $(Q \geq 3)$, respectively]

\begin{tabular}{|c|c|c|c|c|c|c|c|c|c|}
\hline \multirow[b]{2}{*}{ Constant } & \multirow[b]{2}{*}{$n$} & \multicolumn{4}{|c|}{ B3LYP/s } & \multicolumn{4}{|c|}{ BHandH/s } \\
\hline & & $n_{\mathrm{w}}$ & $n_{\mathrm{m}}$ & $n_{\mathrm{p}}$ & $Q_{\mathrm{av}}$ & $n_{\mathrm{w}}$ & $n_{\mathrm{m}}$ & $n_{\mathrm{p}}$ & $Q_{\text {av }}$ \\
\hline${ }^{1} J(\mathrm{~F}, \mathrm{C})$ & 20 & 0 & 0 & 20 & 4.6 & 13 & 7 & 0 & 0.8 \\
\hline${ }^{2} J(\mathrm{~F}, \mathrm{H})$ & 8 & 8 & 0 & 0 & 0.4 & 7 & 1 & 0 & 0.5 \\
\hline $2 J(F, C)$ & 24 & 0 & 6 & 18 & 3.9 & 13 & 9 & 2 & 1.3 \\
\hline${ }^{2} J(\mathrm{~F}, \mathrm{C})^{a}$ & 13 & 0 & 6 & 7 & 2.8 & 13 & 0 & 0 & 0.4 \\
\hline${ }^{2} J(\mathrm{~F}, \mathrm{C})^{b}$ & 11 & 0 & 0 & 11 & 5.1 & 0 & 9 & 2 & 2.4 \\
\hline${ }^{2} J(\mathrm{~F}, \mathrm{~F})$ & 6 & 0 & 0 & 6 & 6.2 & 5 & 1 & 0 & 0.6 \\
\hline${ }^{3} J(\mathrm{~F}, \mathrm{H})$ & 15 & 2 & 7 & 6 & 2.6 & 7 & 6 & 2 & 1.5 \\
\hline${ }^{3} J(\mathrm{~F}, \mathrm{H})^{a}$ & 3 & 0 & 3 & 0 & 2.1 & 3 & 0 & 0 & 0.4 \\
\hline${ }^{3} J(\mathrm{~F}, \mathrm{H})^{b}$ & 12 & 2 & 4 & 6 & 2.8 & 4 & 6 & 2 & 1.8 \\
\hline $3(\mathrm{~F}, \mathrm{C})$ & 15 & 4 & 6 & 5 & 2.1 & 6 & 8 & 1 & 1.4 \\
\hline${ }^{3} J(\mathrm{~F}, \mathrm{~F})$ & 3 & 0 & 1 & 2 & 3.8 & 0 & 2 & 1 & 2.7 \\
\hline
\end{tabular}

${ }^{a}$ Coupling constants for fluoroalkanes other than fluorocyclopropanes. ${ }^{b}$ Coupling constants for fluorocyclopropanes.

values gained for these parameters when using DFT methods involving B3LYP and BHandH functionals come almost exclusively from different calculated contributions of the Fermicontact coupling mechanism to the total constant (Table 8). This finding remains in full agreement with the results of the work by García de la Vega and San Fabián ${ }^{\mathbf{4 0}}$ who have recently treated that problem in more detail.

The values of the collected two-bond fluorine-hydrogen coupling constants have been predicted very well by both B3LYP/s and BHandH/s methods. Their effectiveness expressed by $Q_{\text {av }}$ values has been 0.5 and 0.4 , respectively. Surprisingly, the PBE0/l method has been much less effective in this case.

Next, as it concerns two-bond ${ }^{19} \mathrm{~F}^{13} \mathrm{C}$ couplings, we have found out that, without exception, the recommended $\mathrm{BHandH} /$ $\mathrm{s}$ method has reproduced experimental results much better than B3LYP/s method. On the other hand, the much more costly PBE0/l method provides somewhat better values of these constants, at least for fluoroethanes and fluorocyclopropanes, although this improvement is practically meaningless (Tables 2, 5 and $\mathrm{S} 5 \dagger$ ). One can notice, however, that for fluorocyclopropanes the calculated values of ${ }^{2} J(\mathrm{~F}, \mathrm{C})$ coupling constants are systematically lower than the experimental ones and that the divergences between experimental and calculated values of these constants are larger than in remaining cases. The averaged prediction-quality indicator $\left(Q_{\mathrm{av}}\right)$ for the recommended DFT method calculated separately for fluorocyclopropanes and for other objects are 2.4 and 0.4, respectively (Table 7). Probably, this divergence is a consequence of the structural specificity of cyclopropanes, although the precision of experimental data may play some role in this case as well.

Indeed, a limited precision of some spin-spin coupling data would be a serious deficiency from our point of view. At the
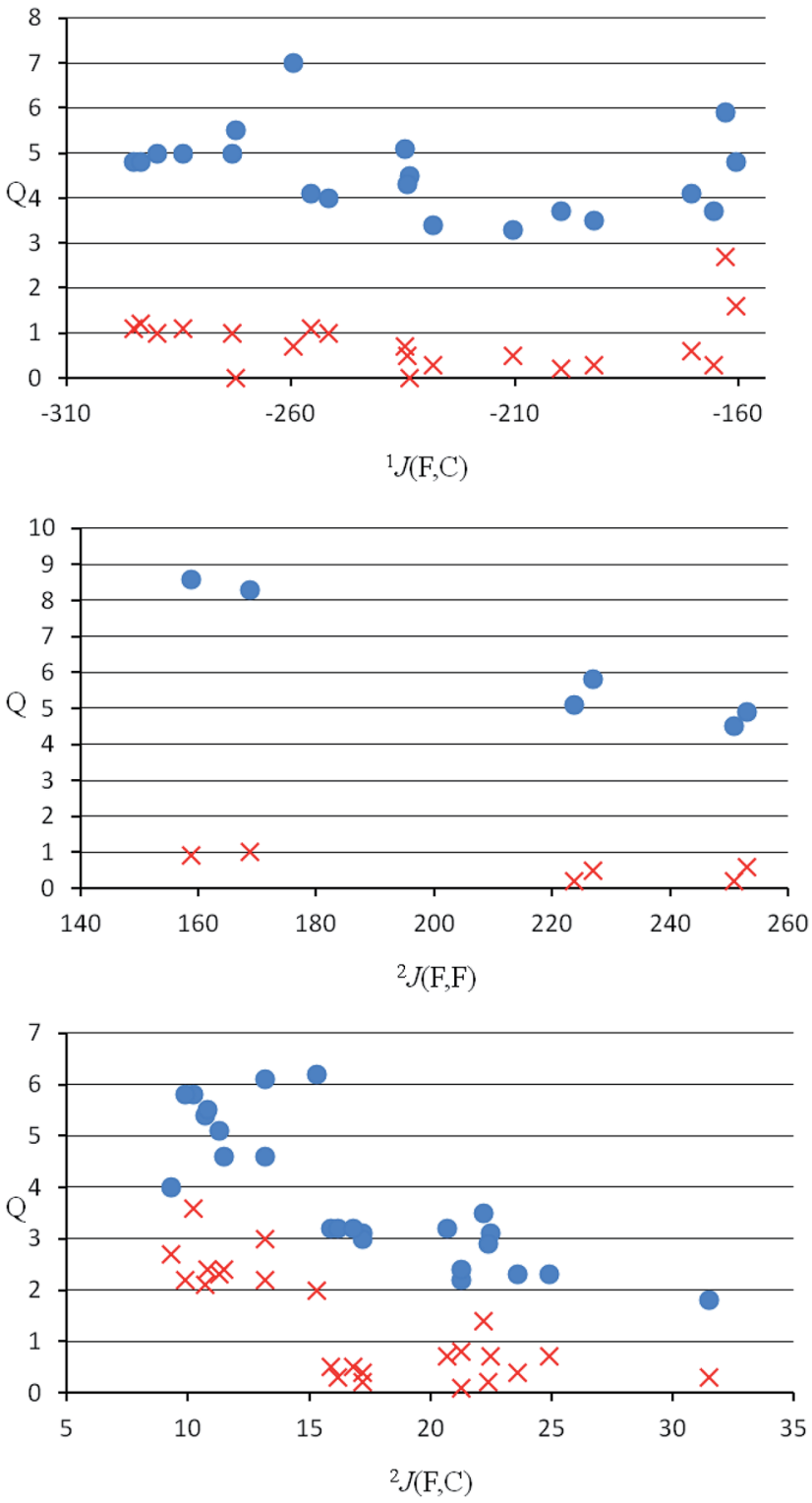

Fig. 1 Accuracy, as defined by $Q$ parameter, of calculated values of different coupling constants; $\times-\mathrm{BHandH} / \mathrm{s},-\mathrm{B} 3 \mathrm{LYP} / \mathrm{s}$.

same time, it seems that in ref. 47, 50 and 53 the values of the ${ }^{19} \mathrm{~F}-{ }^{13} \mathrm{C}$ coupling constants were read out directly from the line positions in the spectra, without lineshape analysis. When several magnetically nonequivalent fluorine nuclei are present in a molecule the carbon signals in its ${ }^{13} \mathrm{C}$ proton-decoupled NMR spectrum are split by several (in general different) carbon-fluorine coupling constants. Such signals have a form of multiplet of several lines. Due to a limited resolution of standard ${ }^{13} \mathrm{C}$ NMR spectra, for certain combinations of coupling constant values, some lines of such multiplets can overlap one another. For example, the C-6 signal of 2,2-difluoronorbornane (X part of ABX spin system) in a ${ }^{13} \mathrm{C}$ NMR spectrum of standard resolution probably has a form of an apparent triplet. Similarly, C-7 signal is probably a doublet of broadened lines. Without performing lineshape analysis the determination of the accurate values of 
Table 8 Selected one-bond fluorine-carbon and two bond fluorine-fluorine spin-spin coupling constants as well as contributions of various mechanisms to these couplings calculated by DFT methods, compared with the measured values of spin-spin constants

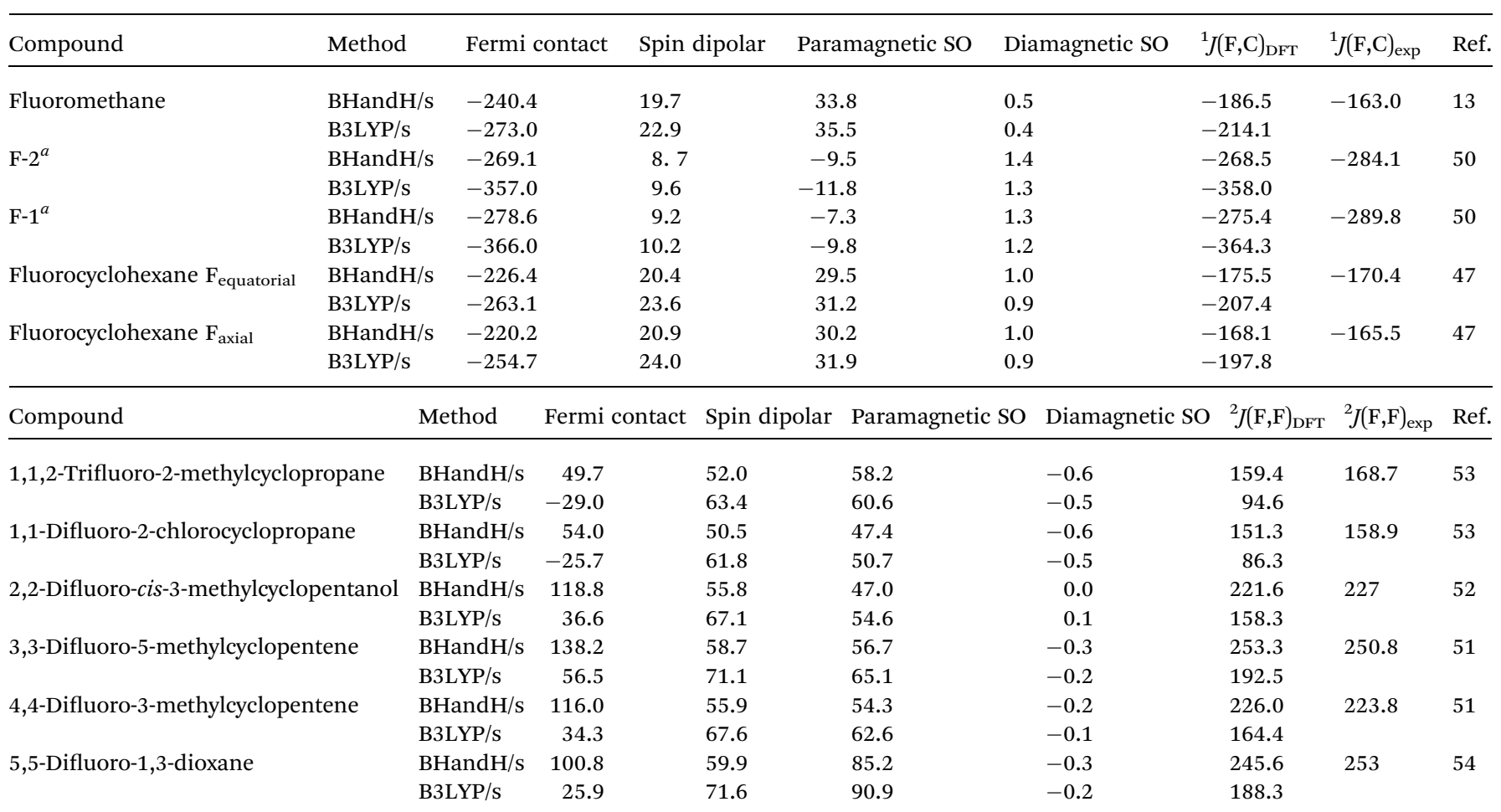

${ }^{a}$ The data concern 1,1-difluoro-2-chlorocyclopropane; for fluorine atom numbering see the formula at Table 5.

individual ${ }^{19} \mathrm{~F}-{ }^{13} \mathrm{C}$ coupling constants from such spectra is impossible.

The problem of line overlapping could also affect the threebond coupling values, especially ${ }^{3} J(\mathrm{~F}, \mathrm{H})$ ones reported for fluorocyclopropanes, where protons are parts of complex spinsystems. In the case of ${ }^{3} J(F, C)$ several coupling constant values have been of the order of the typical linewidths in the ${ }^{13} \mathrm{C}$ NMR spectra. Nevertheless, examination of the results in Tables 5, S5, 6 , S6 and 7 clearly shows that all trends visible in experimental data are well reproduced by the theoretical values obtained by $\mathrm{BHandH} / \mathrm{s}$ method. Out of 15 collected ${ }^{3} J(\mathrm{~F}, \mathrm{H})$ values only two have been poorly predicted and the averaged prediction-quality indicator $Q_{\mathrm{av}}$ was 1.5 (Table 7). Similarly, only one out of 15 ${ }^{3} J(\mathrm{~F}, \mathrm{C})$ values has been poorly predicted and the $Q_{\mathrm{av}}$ indicator amounted to 1.4 (Table 7).

We have additionally noticed that the method suitable for predictions of $J(\mathrm{~F}, \mathrm{X})(\mathrm{X}=\mathrm{H}, \mathrm{C}, \mathrm{F})$ coupling constants yields poor results in the case of ${ }^{1} J(\mathrm{C}, \mathrm{H})$ constants. It seems that in this case, the largest of three basis sets used in this study is required at the final calculation step (Tables 1 and 3). When this basis is used, all three functionals tested work sufficiently well and the result is only poorly dependent on the basis used during geometry optimization. It is somewhat surprising that the results provided by B3LYP/s method $\left(Q_{\mathrm{av}}=0.9\right)$ are only slightly worse than, say, PBE0/1 $\left(Q_{\mathrm{av}}=0.3\right)$. These observations, however, are a by-product of this work and probably need further verification. Quite a different approach to predicting ${ }^{1} J(\mathrm{C}, \mathrm{H})$ values has been proposed recently by Fabián $e t$ al. ${ }^{68}$

\section{Conclusions}

A reliable theoretical prediction of the values of the indirect spin-spin coupling constants involving fluorine nucleus is an important problem for the structural chemistry of fluoroorganic compounds. In this work we have performed theoretical calculations of these NMR parameters for a set of fluoromethanes, fluoroethanes and several fluorocycloalkanes using various DFT methods. In order to analyze the large amount of the obtained data we have adopted a prediction-quality criterion (eqn (1)) allowing the effectiveness of various theoretical methods to be compared. We have found out that the proposed criterion is a very convenient tool, which allows the effectiveness of various theoretical methods to be evaluated in a straightforward and, to some degree, objective manner. Using this criterion, we have concluded that the values of the isotropic indirect spin-spin coupling constants involving a ${ }^{19} \mathrm{~F}$ nucleus are predicted well when using DFT BHandH/s PCM method during molecular geometry optimization and NMR calculations. To be more precise, the use of the $\mathrm{BHandH}$ functional is indispensable only during the calculations of ${ }^{1} J(\mathrm{~F}, \mathrm{C})$ and ${ }^{2} J(\mathrm{~F}, \mathrm{~F})$ parameters. In the case of other coupling constants involving fluorine, the results gained when using $\mathrm{BHandH} / \mathrm{s}$ method are also better than those achieved with the methods using B3LYP or PBE0, although some of the results of two latter functionals are of comparable quality. Application of larger basis sets like $\mathrm{m}, 1$ or other specialized sets as $\mathrm{m}^{\prime}=$ aug-cc-pVTZ-J, ${ }^{69}$ suggested by the referee, seems to be unjustified, as it enhances 
computation time and simultaneously does not guarantee achievement of better results. We believe that the recommended $\mathrm{BHandH} / \mathrm{s}$ method yields the results which are sufficiently accurate and reliable, so that they can be useful in solving various chemical problems by combining NMR measurements and DFT calculations. At the same time, it is quite probable that the recommended method is not yet the optimal one. It seems, however, that further improvement of the experiment/theory agreement demands, first of all, inclusion of the effects of molecular vibrations, molecular collisions and a more elaborate description of impact of other medium effects, into the theoretical model.

Finally, two problems, which are to some degree connected with the subject of this study, are to be mentioned. We have noticed that, for fluorinated carbons, independently of the functional used, a large basis set is necessary to obtain ${ }^{1} J(C, H)$ values being close to the experimental ones. Secondly, some introductory tests seem to point out that the BHandH functional is less effective than B3LYP or PBE0 in predicting carbon and fluorine chemical shifts, but this conclusion has yet to be tested.

\section{Acknowledgements}

This work was financially supported by Warsaw University of Technology.

\section{References}

1 P. Kirsch, Modern Fluoroorganic Chemistry: Synthesis, Reactivity, Applications, Wiley Online Library, 2005, ch. 1, DOI: $10.1002 / 352760393 x$.

2 J. A. Ma and D. Cahard, Chem. Rev., 2004, 104, 6119-6146.

3 J. Scheirs, Modern Fluoropolymers, John Wiley and Sons, Chichester, 1997.

4 R. C. Terrell, Anesthesiology, 2008, 108, 531-533.

5 K. A. Ampt, R. L. Aspers, M. Jaeger, P. E. Geutjes, M. Honing and S. S. Wijmenga, Magn. Reson. Chem., 2011, 49, 221-230.

6 Y. G. Gakh, A. A. Gakh and A. M. Gronenborn, Magn. Reson. Chem., 2000, 38, 551-558.

7 J. L. Kitevski-LeBlanc and R. S. Prosser, Prog. Nucl. Magn. Reson. Spectrosc., 2012, 62, 1-33.

8 R. J. Abraham and R. H. Kemp, J. Chem. Soc. B, 1971, 12401245.

9 R. D. Norris and G. Binsch, J. Am. Chem. Soc., 1973, 95, 182190.

10 B. Zhang, L. Li, F. Mikes, Y. Koike, Y. Okamoto and P. L. Rinaldi, J. Fluorine Chem., 2013, 147, 40-48.

11 A. Gryff-Keller and P. Szczeciński, RSC Adv., 2014, 4, 2729027296.

12 A. Gryff-Keller and P. Szczeciński, J. Mol. Struct., 2015, 1091, 222-227.

13 P. Lantto, J. Kaski, J. Vaara and J. Jokisaari, Chem.-Eur. J., 2000, 6, 1395-1406.

14 A. A. Auer, J. Gauss and J. F. Stanton, J. Chem. Phys., 2003, 118, 10407-10417.
15 V. Barone, P. F. Provasi, J. E. Peralta, J. P. Snyder, S. P. A. Sauer and R. H. Contreras, J. Phys. Chem. A, 2003, 107, 4748-4754.

16 M. Jaszunski, Chem. Phys. Lett., 2004, 385, 122-126.

17 J. E. Del Bene, I. Alkorta and J. Elguero, J. Chem. Theory Comput., 2009, 5, 208-216.

18 F. Nozirov, T. Kupka and M. Stachow, J. Chem. Phys., 2014, 140, 144303.

19 M. E. Harding, M. Lenhart, A. A. Auer and J. Gauss, J. Chem. Phys., 2008, 128, 244111.

20 A. Gryff-Keller, Concepts Magn. Reson., Part A, 2011, 38, 289307.

21 P. R. Rablen, S. A. Pearlman and J. Finkbiner, J. Phys. Chem. A, 1999, 103, 7357-7363.

22 D. J. Giesen and N. Zumbulyadis, Phys. Chem. Chem. Phys., 2002, 4, 5498-5507.

23 T. Helgaker, M. Watson and N. C. Handy, J. Chem. Phys., 2000, 113, 9402-9409.

24 A. Bagno and G. Saielli, Theor. Chem. Acc., 2007, 117, 603619.

25 M. W. Lodewyk, M. R. Siebert and D. J. Tantillo, Chem. Rev., 2012, 112, 1839-1862.

26 A. Dokalik, H. Kalchhauser, W. Mikenda and G. Schweng, Magn. Reson. Chem., 1999, 37, 895-902.

27 S. Komorovsky, M. Repisky, O. L. Malkina, V. G. Malkin, I. M. Ondik and M. A. Kaupp, J. Chem. Phys., 2008, 128, 104101/1-104101/15.

28 A. Wodynski, A. Gryff-Keller and M. Pecul, J. Chem. Theory Comput., 2013, 9, 1909-1917.

29 G. Casella, A. Bagno, S. Komorovsky, M. Repisky and G. Saielli, Chem.-Eur. J., 2015, 21, 18834-18840.

30 W. Adcock, D. Lunsmann, J. E. Peralta and R. H. Contreras, Magn. Reson. Chem., 1999, 37, 167-172.

31 K. B. Wiberg and K. W. Zilm, J. Org. Chem., 2001, 66, 28092817.

32 J. C. C. Chan and H. Eckert, J. Mol. Struct.: THEOCHEM, 2001, 535, 1-8.

33 G. Saielli, R. Bini and A. Bagno, RSC Adv., 2014, 4, 4160541611.

34 G. Saielli, R. Bini and A. Bagno, Theor. Chem. Acc., 2012, 131, 1140.

35 O. L. Malkina, D. R. Salahub and V. G. Malkin, J. Chem. Phys., 1996, 105, 8793-8800.

36 A. Frish, M. J. Frish and G. W. Trucks, Gaussian 03 User's Reference, Gaussian, Inc., 2003.

37 A. D. Becke, J. Chem. Phys., 1993, 98, 1372-1377.

38 M. P. Freitas and M. Buehl, J. Fluorine Chem., 2012, 140, 8287.

39 J. D. Vilcachagua, L. C. Ducati, R. Rittner, R. H. Contreras and C. F. Tormena, J. Phys. Chem. A, 2011, 115, 1272-1279.

40 J. M. García de la Vega and J. San Fabián, Mol. Phys., 2015, 113, 1924-1936.

41 A. D. Becke, J. Chem. Phys., 1993, 98, 5648-5652.

42 C. Adamo and V. Barone, J. Chem. Phys., 1999, 110, 61586170.

43 S. N. Maximoff, J. E. Peralta, V. Barone and G. E. Scuseria, J. Chem. Theory Comput., 2005, 1, 541-545. 
44 T. W. Keal, T. Helgaker, P. Sałek and D. J. Tozer, Chem. Phys. Lett., 2006, 425, 163-166.

45 F. Jensen, J. Chem. Theory Comput., 2006, 2, 1360-1369.

46 K. Jackowski and W. T. Raynes, J. Chem. Res., Synop., 1977, 66.

47 R. J. Abraham, M. Edgar, L. Griffiths and R. L. Powell, J. Chem. Soc., Perkin Trans. 2, 1995, 561-567.

48 D. D. Elleman, L. C. Brown and D. Williams, J. Mol. Spectrosc., 1961, 7, 307-321.

49 A. Foris, Magn. Reson. Chem., 2001, 39, 386-398.

50 W. S. Brey, Magn. Reson. Chem., 2008, 46, 480-492.

51 W. R. Dolbier Jr and S. F. Sellers, J. Am. Chem. Soc., 1982, 104, 2494-2497.

52 A. A. P. Bravo, G. Cavicchio, M. Frigerio and F. Viani, Tetrahedron, 1992, 48, 8523-8540.

53 W. S. Brey, D. Richardson, B. Bechtel and A. Aksenov, Magn. Reson. Chem., 2007, 45, 205-219.

54 G. Binsch, E. L. Eliel and S. Mager, J. Org. Chem., 1973, 38, 4079-4081.

55 K. Jackowski, M. Kubiszewski and W. Makulski, J. Mol. Struct., 2002, 614, 267-272.

56 M. Kubiszewski, W. Makulski and K. Jackowski, J. Mol. Struct., 2005, 737, 7-10.

57 M. Kubiszewski, W. Makulski and K. Jackowski, J. Mol. Struct., 2004, 704, 211-214.

58 S. G. Frankiss, J. Phys. Chem., 1963, 67, 752-755.
59 W. Adcock, D. I. Angus and D. A. Lowe, Magn. Reson. Chem., 1996, 34, 675-680.

60 J. Tomasi, B. Mennucci and R. Cammi, Chem. Rev., 2005, 105, 2999-3093.

61 M. J. Frisch, G. W. Trucks, H. B. Schlegel, G. E. Scuseria, M. A. Robb, J. R. Cheeseman, J. A. Montgomery Jr, T. Vreven, K. N. Kudin and J. C. Burant, et al., Gaussian 03, Gaussian, Inc., Wallingford CT, 2004.

62 T. W. Keal, D. J. Tozer and T. Helgaker, Chem. Phys. Lett., 2004, 391, 374.

63 M. P. Freitas, M. Buehl and D. O'Hagan, Chem. Commun., 2012, 48, 2433-2435.

64 D. Nori-Shargh and J. E. Boggs, Struct. Chem., 2011, 22, 253262.

65 P. F. Provasi and S. P. A. Sauer, J. Chem. Theory Comput., 2006, 2, 1019-1027.

66 W. J. E. Parr and T. Schaefer, Acc. Chem. Res., 1980, 13, 400406.

67 L. C. Ducati, R. H. Contreras and C. F. Tormena, J. Phys. Chem. A, 2012, 116, 4930-4933.

68 J. San Fabián, J. M. García de la Vega, R. Suardíaz, M. Fernández-Oliva, C. Pérez, R. Crespo-Otero and R. H. Contreras, Magn. Reson. Chem., 2013, 51, 775-787.

69 K. L. Schuchardt, B. T. Didier, T. Elsethagen, L. Sun, V. Gurumoorthi, J. Chase, J. Li and T. L. Windus, J. Chem. Inf. Model., 2007, 47, 1045-1052. 